\title{
71 år gammel mann med alvorlig sirkulasjonssvikt etter hjertestans
}

\author{
En 71 år gammel tidligere frisk mann ble innlagt med sirkulasjonssvikt \\ og antatt kardiogent sjokk etter hjertestans og langvarig gjenoppliving.
}

Se kommentar side 165 og kunnskapsprøve på www.tidsskriftet.no/quiz

\author{
Anders Wetting Carlsen \\ anders.wetting.carlsen@stolav.no \\ Avdeling for thoraxanestesi og intensivmedisin \\ St. Olavs hospital \\ 7006 Trondheim \\ Bjørn Olav Haugen \\ Klinikk for hjertemedisin \\ Pål Klepstad \\ Intensivavdelingen \\ St. Olavs hospital \\ og \\ Institutt for sirkulasjon og bildediagnostikk \\ Norges teknisk-naturvitenskapelige universitet
}

12 dager før den aktuelle hendelsen ble 71åringen innlagt ved et lokalsykehus med fremreveggsinfarkt. På grunn av lang sykehistorie og begynnende Q-utvikling i V1-V3 fikk han ikke trombolytisk behandling. Han var smertefri under oppholdet, og klinisk var det ingen tegn til hjertesvikt. Ekkokardiografi viste god venstre ventrikkel-funksjon med kun antydning til redusert kontraktilitet apikoseptalt. I forløpet steg kreatinkinase MB-fraksjon (CK-MB) til maksimalt 145,0 $\mu \mathrm{g} / \mathrm{l}$ (referanseverdi $<0,5 \mu \mathrm{g} /$ l). I løpet av innleggelsen ble han belastet til $175 \mathrm{~W}$ med arbeids-EKG, uten at det var tegn på iskemi. Man valgte derfor å avstå fra henvisning til angiografisk utredning. Pasienten ble inkludert i PLATO-studien, fikk metoprolol og ble utskrevet og kunne reise hjem i fin form.

I PLATO-studien (1) tar man sikte på å sammenlikne klopidogrel og en ny, reversibel platehemmer (AZD6140), begge i kombinasjon med acetylsalisylsyre, med tanke på risiko for kardiovaskulær død ved akutt koronarsyndrom.

Det aktuelle startet med bevitnet hjertestans ved 15-tiden dag 0 . Hjerte-lunge-redning ble umiddelbart satt i gang av kommunelegen, som tilfeldigvis var på stedet. Ambulansepersonell med defibrillator ankom etter ca. 25 minutter. Primær rytme på skop var ventrikkelflimmer, og pasienten ble defibrillert to ganger under pågående hjerte-lunge-redning før det ble omslag til pulsløs elektrisk aktivitet. Man fortsatte videre med hjerte-lunge-redning inntil pasienten etter ytterligere ca. 25 minutter fikk pulsgivende rytme. Til tross for egenrytme våknet han ikke, og han ble intubert av luftambulanselege før transport til St. Olavs hospital. Under transporten startet man forsiktig nedkjøling. Grunnet motorisk uro valgte man å ekstubere pasienten før ankomst i mottakelsen.

Langvarig resusciteringstid er forbundet med økt risiko for nevrologisk skade. Som hovedregel skal hjertestanspasienter som ikke våkner i løpet av ti minutter etter gjenvunnet egensirkulasjon behandles med terapeutisk hypotermi. Behandlingen krever sedasjon, respiratorbehandling og muskelrelaksasjon. Motorisk uro kunne her tolkes som at pasienten var i ferd med å våkne, men kunne også være symptom på inadekvat cerebral oksygenering. Vurderingen kan være vanskelig, særlig under helikoptertransport, der mulighetene for å kommunisere med pasienten er begrenset. Man valgte $i$ dette tilfellet å ekstubere pasienten for å se om han var under oppvåkning. Alternativt kunne man valgt å sedere ham for å unngå øt cerebralt oksygenbehov pga. uro. At det var startet nedkjøling, er et ytterligere argument mot å ekstubere.

Ved ankomst St. Olavs hospital kl 1645 fikk man ingen adekvat kontakt med pasienten, som var motorisk urolig. Han hadde puls på $110 / \mathrm{min}$, blodtrykk $80 / 50 \mathrm{~mm} \mathrm{Hg}$ og var dårlig sirkulert perifert, med kalde ekstremiteter. Man hørte spredte pipe- og knatrelyder over begge lungeflater, ellers var det intet å anmerke ved klinisk undersøkelse. EKG var tilnærmet uendret fra innleggelsen i lokalsykehuset. Ekkokardiografi viste akinesi og noe fortynning av veggen septalt og akinesi apikalt. Ejeksjonsfraksjonen ble bedømt visuelt til ca. $35 \%$. Rutineblodprøver tatt ved innkomst (referanseverdier angitt $i$ parentes) viste hvite blodceller 18,1.10\% $/$ (3,7-10,0 $\left.10^{9} / \mathrm{l}\right)$, D-dimer 21,0 mg/l $<<0,5$ $\mathrm{mg} / \mathrm{ll}$ og troponin- $0,324 \mu \mathrm{g} / \mathrm{l}(<0,010 \mu \mathrm{g} / \mathrm{ll}$, for øvrig var det normale funn. Initial blodgass viste $\mathrm{pH} \mathrm{7,12} \mathrm{(7,35-7,45),} \mathrm{pCO}_{2} 7,58 \mathrm{kPa}$
(4,5-6,0 kPa), pO 19,4 kPa (11,0-14,0 kPa), $\mathrm{BE}-10,3 \mathrm{mmol} / \mathrm{l}(-3-3 \mathrm{mmol} / \mathrm{l}), \mathrm{HCO}_{3}$ 17,5 $\mathrm{mmol} / \mathrm{l}(21-27 \mathrm{mmol} / \mathrm{l})$ og laktat $7,1 \mathrm{mmol} / \mathrm{l}$ $10,5-2,2 \mathrm{mmol} / \mathrm{l})$.

Med god primærbehandling prehospitalt lyktes det oss å reetablere spontan sirkulasjon på tross av langvarig gjenoppliving. Komparentopplysninger ga ikke holdepunkter for å anta at han hadde hatt brystsmerter før sirkulasjonsstansen, og man antok at hjertestansen ble utløst av senarytmi heller enn av et nytt infarkt. Tentativt mistenkte man dessuten at pasienten var i ferd med å utvikle kardiogent sjokk.

Han ble sedert og reintubert og deretter overflyttet til Klinikk for hjertemedisin for koronar angiografi. Man fant der en okkludert liten venstre koronararterie lleft anterior descending artery, LAD). Funnet var forenlig med det faktum at han hadde gjennomgått fremreveggsinfarkt knapt to uker tidligere. I tillegg ble det påvist en proksimal stenose $i$ en stor intermediærgren. Man konkluderte med at denne nå hadde forårsaket et ferskt infarkt. Stenosen ble behandlet med perkutan koronar intervensjon (PCI) med konvensjonell stent, med godt angiografisk resultat. Etter dette gjenvant pasienten adekvat blodtrykk og diurese og ble overflyttet til Intensivavdelingen for terapeutisk hypotermibehandling.

Ut fra funn ved koronar angiografi samt stigning og fall i troponin-T- og CK-MB-verdiene (maksimumsverdi i forløpet på hhv. 1 $280 \mu \mathrm{g} / \mathrm{l}$ og 72,5 $\mu \mathrm{g} / \mathrm{l})$ fikk pasienten mest sannsynlig hjertestans i forbindelse med et nytt hjerteinfarkt, ikke etter senarytmi, som først antatt. Dette er et diagnostisk viktig skille - fordi pasienter som overlever arytmiutløst hjertestans, kan være aktuelle for implantasjon av intrakardial defibrillator (intracardial device, ICD).

Med bakgrunn i pasientens initiale bevisstløshet etter gjenvunnet egenrytme samt nedsatte cerebrale funksjon før reintubasjon fant vi det indisert med terapeutisk hypotermibehandling med måltemperatur $33^{\circ} \mathrm{C}$, fortrinnsvis i ett døgn. Behandling med moderat terapeutisk hypotermi etter standardisert protokoll hos hjertestanspasienter som er bevisstløse etter vellykket gjenoppliving er tidligere omtalt i Tidsskriftet (2). Det har vist seg at denne behandlingen både gir økt overlevelse og redusert nevrologisk sekvele. I tillegg ble det igangsatt platehemmende 
behandling med abciximabinfusjon over 12 timer etter PCI-behandling.

Dagen etter innkomst (dag 1) var pasientens tilstand forverret. Respiratorisk hadde han kombinert oksygenerings- og ventileringssvikt, noe som krevde høye respiratortrykk og $100 \%$ oksygen. Blodgassanalyser viste acidose med både respiratorisk og metabolsk komponent. Sirkulatorisk var han økende ustabil og ble innsatt på noradrenalin, dopamin og dobutamin i kombinasjon. Klinisk ble han oppfattet som karkonstringert, med kjølige ekstremiteter. Ved ekkokardiografi var det dårlig innsyn, men man fikk inntrykk av en relativt godt fungerende venstre ventrikkel med ejeksjonsfraksjon $>40 \%$. Røntgen thorax viste tegn til stuving og bilateral pleuravæske. Ultralyd abdomen viste dessuten «uforklarlig» ascites. Terapeutisk hypotermi ble avsluttet etter 12 timer pga. ustabil hemodynamikk.

Ved ekkokardiografi fikk man begrenset innsyn, og kun fra subkostal posisjon, og ville derfor ikke trekke for bastante konklusjoner fra undersøkelsen. Arbeidshypotesen var multiorgansvikt på bakgrunn av en sviktende venstre ventrikkel. Levosimendan og aortaballongpumpe ble vurdert, men man valgte å se det an pga. usikre funn ved ekkounders $\varnothing$ kelsen. Blant personalet spredte det seg en økende følelse av at pasienten ikke kom til å overleve, og han ble «holdt flytende» med væskeinfusjon samt vasopressor og positivt inotrope medikamenter i høy dosering.

På morgenen dag 2 hadde pasientens tilstand forverret seg ytterligere. Han hadde vedvarende oksygenerings- og ventileringssvikt samt sirkulatorisk svikt, med middelarterietrykk $37 \mathrm{~mm} \mathrm{Hg}$. I tillegg var det tilkommet anurisk nyresvikt med stigende nivåer av kreatinin og kalium samt økende acidose og CRP-stigning til $208 \mathrm{mg} / \mathrm{l}$. Ekkokardiografi viste en relativt godt kontraherende venstre ventrikkel, dog fremdeles ut fra suboptimalt innsyn.

Pasientens tilstand var til nå først og fremst blitt oppfattet som et behandlingsrefraktært kardiogent sjokk med ledsagende multiorgansvikt etter gjennomgått hjerteinfarkt/stans. Lavt blodtrykk, radiologiske «svikttegn» og klinisk mistanke om uttalt karkonstriksjon talte for kardiogent sjokk som årsak til sirkulasjonskollapsen. Det som talte imot, var den ekkokardiografiske bedømmingen av venstre ventrikkel, som antydet god kontraktilitet. Sistnevnte undersøkelse var dog teknisk vanskelig og tolkingen usikker.

Pasienten ble på dette tidspunktet oppfattet som kritisk syk, og vi var usikre på om det var riktig å fortsette behandlingen. Men ut fra hans tidligere historie (frisk, fysisk sprek) og de ekkokardiografiske funnene valgte vi likevel å satse videre.

Etter sikring av adekvate dyrkingsprøver fikk han ceftriakson og metronidazol mot mulig aspirasjonspneumoni.

For å få bedre innblikk i pasientens hemodynamiske tilstand ble det lagt inn et pulmonalarteriekateter (Swan-Ganz-kateter). Initiale målinger viste et hyperdynamisk bilde med høyt hjerteminuttvolum (7 1/min), relativt lavt fyllingstrykk i venstre ventrikkel (12 mm Hg) og ekstremt lav systemvaskulær motstand på $250 \mathrm{dyn} \cdot \mathrm{sek} \cdot \mathrm{cm}^{-5}$ (referanseverdi 800-1 $\left.200 \mathrm{dyn} \cdot \mathrm{sek} \cdot \mathrm{cm}^{-5}\right)$. Disse funnene var lite forenlig med kardiogent sjokk, de likner heller det bildet man ser ved sirkulasjonssvikt forårsaket av sepsis.

Med endret forståelse av sirkulasjonens patofysiologi ble vi i stand til i større grad å skreddersy det videre behandlingsopplegget. Vi måtte nå forkaste kardiogent sjokk som hypotese og erkjenne at vi sto overfor alvorlig systemisk inflammatorisk responssyndrom (SIRS) med grav vasoplegi og kapillærlekkasje, som hovedsakelig krevde væskeresuscitering og høydose vasopressor. I tillegg startet vi lavdosebehandling med kortikosteroider (hydrokortison $50 \mathrm{mg} \times 4$ intravenøst) i håp om å bedre katekolaminresponsen (3). Grunnet nyresvikt ble det lagt inn dialysekateter og startet kontinuerlig hemofiltrasjon.

Pasienten responderte umiddelbart og godt på ytterligere væskestøt og høydose noradrenalin-infusjon. Middelarterietrykket steg raskt fra $37 \mathrm{~mm} \mathrm{Hg}$ til $50 \mathrm{~mm} \mathrm{Hg}$ og blandet venøs oksygenmetning $\left(\mathrm{SvO}_{2}\right)$ fra $60 \%$ til $70 \%$.

På dag 5 var pasienten $i$ klar bedring. Respiratorisk krevde han lavere respiratortrykk, og $\mathrm{FiO}_{2}$ var redusert til 0,5. Røntgen thorax viste bilateral pleuravæske, men man avsto fra å legge pleuradren grunnet blødningstendens. Sirkulatorisk var han stabil med en liten dose noradrenalin, men med et betydelig (iatrogent) væskeoverskudd, som ble estimert til 27 l. Han var tørr og varm i huden og hadde normal kapillærfyllingstid. I tillegg hadde han begynnende egendiurese.

Den kliniske fremgangen fortsatte, og på dag 8 var pasienten uten vasoaktive medikamenter. Han hadde egendiurese på 1200 $\mathrm{ml} /$ døgn, og kontinuerlig hemofiltrasjon ble seponert. Grunnet forventet langvarig respiratoravvenning og usikkerhet vedrørende cerebral funksjon ble pasienten trakeotomert dag 11.

Dag 12 var all sedasjon stoppet, og pasienten viste etter hvert tegn til å våkne opp. Han ble overflyttet til Hjertemedisinsk overvåkingsavdeling, der man fortsatte med respiratoravvenning, væsketrekk og mobilisering. Pasienten ble dekanylert dag 19 og tilbakeført til lokalsykehus dag 25.

Seks måneder etter utskrivning er pasienten i god form. Han forteller at hukommelsen er like god som før. Han er fysisk aktiv og er nå motivert for å prøve seg som deltaker i Birkebeinerrennet.

\section{Diskusjon}

The American College of Chest Physicians (ACCP) og The Society of Critical Care Medicine (SCCM) gikk i 1992 sammen om å definere kriteriene for systemisk inflammatorisk respons-syndrom (SIRS), sepsis, alvorlig sepsis, septisk sjokk og multiorgansvikt (4). Kriteriene beskriver en systemisk respons på et etiologisk vidt årsaksspekter infeksiøst, toksisk, traumatisk, iskemisk eller inflammatorisk - og krever $\geq 2$ av følgende:

- Pulsfrekvens $>90 / \mathrm{min}$

- Temperatur $<36{ }^{\circ} \mathrm{C}$ eller $>38^{\circ} \mathrm{C}$

- Respirasjonsfrekvens > 20/min eller $\mathrm{PaCO}_{2}<4,3 \mathrm{kPa}$

- Hvite blodceller $<4 \cdot 10^{9} / 1$ eller $>12 \cdot 10^{9} / 1$

Sepsis defineres som påvist eller mistenkt infeksjon i kombinasjon med minst to av kriteriene for syndromet.

Vår pasient oppfylte allerede ved innkomst minst to av fire kriterier (pulsfrekvens 110/min og hvite blodceller $\left.18,1 \cdot 10^{9} / 1\right)$. Kroppstemperaturen kunne ikke brukes som kriterium fordi man hadde startet nedkjøling prehospitalt. Respirasjonsfrekvensen ble dessverre ikke nedtegnet i journalen før pasienten ble reintubert.

Med bakgrunn i sykdomshistorie, kliniske og radiologiske funn, samt usikkerhet angående ekkokardiografiske funn, ble pasientens tilstand initialt feiltolket som akutt kardiogent sjokk. Ved sirkulatorisk kollaps er det viktig å identifisere årsaksforhold for å kunne gi mest mulig optimal behandling, og hypotensjon i tidlig fase gir i seg selv økt mortalitet hos pasienter med gjennomgått hjertestans (5). Retrospektivt er det åpenbart at vi med tidligere invasiv monitorering med transøsofageal ekkokardiografi, pulmonalarteriekateter eller pulskonturanalyse (PiC$\mathrm{CO})$ kunne stilt diagnosen tidligere (6). Ved alle disse monitoreringsmetodene kan man måle hjertets minuttvolum $(\mathrm{CO})$, og når man i tillegg kjenner middelarterietrykk (MAP) og sentralt venetrykk (CVP), kan man utlede systemisk vaskulær motstand (SVR) ved hjelp av følgende formel:

$$
S V R=\frac{(M A P-C V P) \cdot 80}{C O}\left[\mathrm{dyn} \cdot \mathrm{sek} \cdot \mathrm{cm}^{-5}\right]
$$

Den systemiske vaskulære motstand (SVR) er et uttrykk for de prekapillære arteriolenes samlede motstand og er, sammen med volumstatus og myokardial kontraktilitet, en sentral faktor for bestemmelse av blodtrykk og dermed organperfusjon. Kasuistikken illustrerer således viktigheten av slik monitorering, særlig i tilfeller med divergerende kliniske og parakliniske funn.

Sepsis/septisk sjokk var en aktuell differensialdiagnose hos denne pasienten, men den tidlige symptomutviklingen og negative dyrkingssvar talte imot at sirkulasjonssvikten var infeksiøst betinget.

Både hjerteinfarkt per se og hjertestans med vellykket gjenoppliving kan gi opphav 


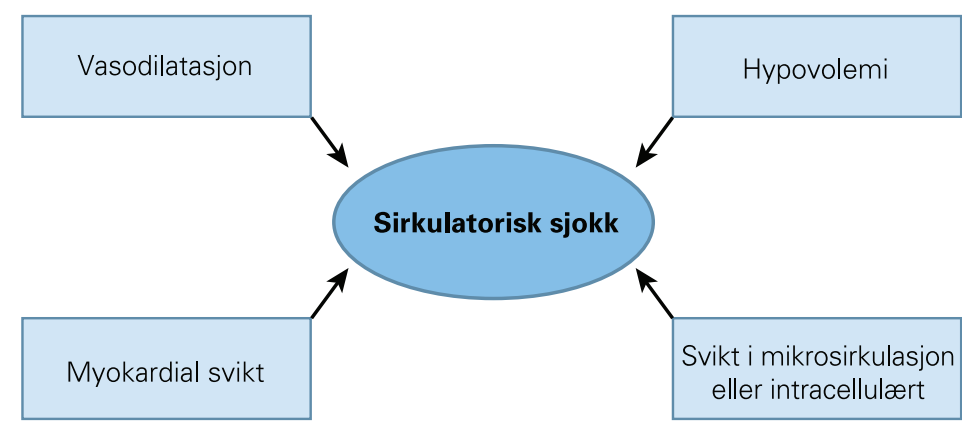

Figur 1 Sirkulasjonssvikt ved systemisk inflammatorisk respons-syndrom (SIRS) - en sammensatt tilstand

til SIRS-tilstander (7), slik vi mener tilfellet var hos vår pasient. Langvarig gjenoppliving og generell vevshypoksi har potensial for a utløse komplekse immunologiske kaskadeeffekter som kan manifestere seg med redusert kardial kontraktilitet, generell vasoplegi, økt kapillær permeabilitet og/eller intracellulær svikt (fig 1). Klinisk kan dette arte seg svært forskjellig - alt fra lette symptomer til fulminant multiorgansvikt og død. Det er derfor viktig å være oppmerksom på at akutt hjertesykdom på samme måte som andre sykdommer og skader kan forårsake en SIRS-reaksjon. Behandlingen ved en slik tilstand er grunnleggende ulik behandlingen ved kardiogent sjokk. Dette understreker betydningen av å skille klinisk mellom pasienter med kardiogent sjokk og pasienter med sirkulasjonskollaps som del av en SIRS-reaksjon.

Sentralt i patogenesen bak systemisk inflammatorisk respons-syndrom finner vi en rekke proinflammatoriske cytokiner som utskilles fra vevsmakrofager, monocytter, mastceller, trombocytter og endotelceller, og som har både lokale og systemiske effekter. Foruten å indusere feber og frigjøring av stresshormoner (antidiuretisk hormon, noradrenalin, aktivering av renin-angiotensinaldosteron-systemet) fremmer de syntese av ulike akuttfaseproteiner i leveren. Akuttfaseproteinenes funksjon er ikke fullt ut forstått. De spiller sannsynligvis en viktig rolle i kroppens selvforsvar, men bidrar også i negativ retning når immunsystemet «skyter over mål», som ved alvorlig SIRS-tilstand (7). De proinflammatoriske cytokinene aktiverer $\mathrm{i}$ tillegg koagulasjonskaskaden og komplementsystemet og stimulerer til frigjøring av nitrogenoksid (NO), plateaktiverende faktor, prostaglandiner og leukotriener. Proinflammatoriske cytokiner hemmer dessuten det fibrinolytiske system. Kombinasjonen gir økt risiko for disseminert intravaskulær koagulasjon (DIC), med økt blødnings- og trombosetendens og ledsagende endeorgansvikt. Komplementaktivering fører til vasodilatasjon og økt kapillær permeabilitet, men bidrar også indirekte til inflammasjon gjennom å stimulere til ytterligere «cytokinstorm». Tilgjengelige data tyder sterkt på at nitrogenoksid spiller en nøkkelrolle når det gjelder vasodilatasjonen og den katekolaminrefraktære hypotensjonen man ser ved systemisk inflammatorisk responssyndrom ved septisk sjokk (8). Muligens er denne patofysiologiske mekanismen overførbar også til alvorlige ikke-infeksiøse SIRS-tilstander.

Lærdommene som kan trekkes fra denne kasuistikken er flere. På generell basis viser den at det ved akutt sirkulasjonssvikt er viktig å kartlegge de patofysiologiske forhold som ligger til grunn. På en intensivavdeling kommer man i de fleste tilfeller frem til riktig diagnose ved å integrere informasjon fra klinisk undersøkelse, transtorakal ekkokardiografi og vanlige monitoreringsdata som pulsfrekvens, invasivt blodtrykk, sentralt venetrykk og oksygenmetning. For noen pasienter kreves imidlertid mer invasiv diagnostikk og monitorering, som transøsofageal ekkokardiografi og pulmonalarteriekateter, for å avklare tilstanden. Hos vår pasient var det avgjørende å skille mellom primær kardial svikt og vasoplegi som følge av en alvorlig SIRS-reaksjon i forløpet av hjerteinfarkt, hjertestans og langvarig gjenopplivning. Etter kardiale hendelser er det nærliggende å tenke pumpesvikt når sirkulasjonen svikter. Kasuistikken er derfor en påminnelse om viktigheten av stadig å reevaluere våre tentative diagnoser når kart og terreng ikke stemmer overens.

Mye av det som er publiset rundt SIRSforskning dreier seg om sepsis/septisk sjokk. Mens behandlingsalgoritmer for sepsispasienter er veletablert i klinisk bruk, mangler det tilsvarende retningslinjer for målrettet hemodynamisk optimalisering av pasienter med alvorlig systemisk inflammatorisk responssyndrom etter vellykket resuscitering $(9,10)$.

Pasienten har gitt samtykke til at artikkelen blir publisert.

Oppgitte interessekonflikter: Bjørn Olav Haugen har fătt støtte til kongressdeltakelse av Orion Pharma, som markedsfører levosimendan (Simdax). De andre forfatterne har ingen oppgitte interessekonflikter.
Litteratur

1. Wallentin L, Becker RC, Budaj A et al. Ticagrelor versus clopidogrel in patients with acute coronary syndromes. N Engl J Med 2009; 361: 1045-57.

2. Sunde K, Søreide E, Jacobsen D et al. Terapeutisk hypotermi etter hjertestans redder flere liv! Tidsskr Nor Lægeforen 2004; 124: 925-6.

3. Annane D, Sébille V, Charpentier $C$ et al. Effect of treatment with low doses of hydrocortisone and fludrocortisone on mortality in patients with septic shock. JAMA 2002; 288: 862-71.

4. Bone RC, Balk RA, Cerra FB. Definitions for sepsis and organ failure and guidelines for the use of innovative therapies in sepsis. The ACCP/SCCM Consensus Conference Committtee. American College of Chest Physicians/Society of Critical Care Medicine. Chest 1992; 101: 1644-55.

5. Kilgannon JH, Roberts BW, Reihl LR et al. Early arterial hypotension is common in the post-cardiac arrest syndrome and associated with increased in-hospital mortality. Resuscitation 2008; 79: 410-6.

6. Salem R, Vallee F. Rusca M et al. Hemodynamic monitoring by echocardiography in the ICU: the role of new echo techniques. Curr Opin Crit Care 2008; 14: 561-8.

7. Oppert M, Gleiter $\mathrm{CH}$, Müller $\mathrm{C}$ et al. Kinetics and characteristics of acute phase response following cardiac arrest. Intensive Care Med 1999; 25: cardiac arre $1386-94$

8. Bateman RM, Sharpe MD, Ellis GC. Bench-to-bedside review: microvascular dysfunction in sepsis hemodynamics, oxygen transport, and nitric oxide. Crit Care 2003; 7: 359-73

9. Jones AE, Shapiro NI, Kilgannon JH et al. Goaldirected hemodynamic optimization in the postcardiac arrest syndrome: a systematic review. Resuscitation 2008: 77: 26-9.

10. Neumar RW, Nolan JP, Adrie $C$ et al. Post-cardiac arrest syndrome: epidemiology, pathophysiology, treatment, and prognostication. A consensus statement from the International Liaison Committee on Resuscitation; the American Heart Association Emergency Cardiovascular Care Committee; the Council on Cardiovascular Surgery and Anesthesia; the Council on Cardiopulmonary. Perioperative, and Critical Care; the Council on Clinical Cardiology; and the Stroke Council. Circulation 2008; 118: 2452-83.

Manuskriptet ble mottatt 22.5. 2009 og godkjent 15.10. 2009. Medisinsk redaktør Are Brean. 